\title{
TOOTH LOSS AND RISK FACTORS AMONG ELDERLY VIETAMESE
}

\section{Minh Son Nguyen ${ }^{1,2 a}$, Ülle Voog-Oras ${ }^{1 b}$, Triin Jagomägi ${ }^{1 c}$, Toai Nguyen ${ }^{3 c}$, Jana Olak ${ }^{1 c}$, Mare Saag ${ }^{1 d^{*}}$}

${ }^{1}$ Institute of Dentistry, University of Tartu, Estonia

${ }^{2}$ Department of Prosthodontics, Da Nang University of Medical Technology and Pharmacy, Da Nang, Vietnam

${ }^{3}$ Odonto-Maxillo-Facial Department, Faculty of Stomatology, Hue University of Medicine and Pharmacy, Hue, Vietnam

aDDS, PhD student

${ }^{b} \mathrm{MD}$, PhD, Associate Professor

'DDS, PhD, Associate Professor

${ }^{d} D D S$, PhD, Professor, Head of Institute of Dentistry

Received: April 11, 2016

Cite this article:

Nguyen MS, Voog-Oras Ü, Jagomägi T, Nguyen T, Olak J, Saag M. Tooth loss and risk factors among elderly Vietnamese.

Stoma Edu J. 2016;3(2):178-183.

\section{ABSTRACT}

Introduction: Oral health care systems for older people tend to be reducing tooth loss and saving functional dentition. Elderly Vietnamese had to live under challenging conditions and were not entitled to any dental care for over 30 years due to the Vietnam War. The aim of the current study was to investigate tooth loss and related risk factors among elderly Vietnamese aged 65-74.

Methodology: The sample study was 258 elderly Vietnamese aged 65-74 years old. Each absent tooth was registered as a tooth loss. Risk factors were evaluated based on the Oral Health Questionnaire for adults (WHO, 2013).

Results: The mean tooth loss for the sample was $7.6( \pm 7.0) .27 .1 \%$ of participants had lost $1-3$ teeth, $23.6 \%$ 4-6 teeth, $27.1 \%$ 7-16 teeth and $13.6 \%>16$ teeth; $8.5 \%$ had full dentition. Within each category of predictors, a statistically higher number of lost teeth was found for: the 70-74 age group (Mean \pm SD, 8.8 \pm 7.9$)$; rural residents (8.8 \pm 7.6$)$; time in education $\leq 5$ years $(10.2 \pm 7.7)$; frequency of teeth cleaning

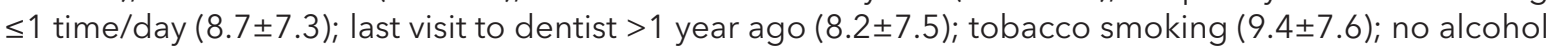
drinking (8.3 \pm 7.2 ). The odds of having $>6$ lost teeth was significantly more frequent among elders with less time in education $(\mathrm{OR}=2.2, p<0.01)$ and tobacco smoking $(\mathrm{OR}=2.8, p<0.01)$.

Conclusion: There are high prevalence and number of tooth loss among elderly Vietnamese. Smoking behaviour and time in education were significantly related to maintaining teeth of the elderly community population.

Keywords: elderly, oral health, risk factors, tooth loss, Vietnamese.

\section{Introduction}

The World Health Organization (WHO) has called for improved oral health among the elderly who are most disposed to oral diseases, including tooth loss. It is estimated that no less than $90 \%$ of the elders are influenced by tooth loss ${ }^{1}$.

According to the $\mathrm{WHO}$, the main aims of oral health care systems for older people are reducing tooth loss and saving functional dentition with at least 20 natural teeth. Tooth loss often has an adverse impact on quality of life and general health ${ }^{2,3}$. Posterior tooth loss results in impaired masticatory performance and temporomandibular disorders, and anterior tooth loss influences social communication owing to reduced aesthetics ${ }^{3-6}$.

Risk factors for tooth loss have been extensively studied. Among health behaviours, several studies have shown that tobacco smoking results in higher tooth loss ${ }^{7,8}$. Others have found that insufficient income can impede oral health care leading to tooth loss 5,9 . Also, the educational background may affect individuals' perception of the importance of oral health behaviours and could be the primary cause of tooth loss among the elders $2,9,10$.

During the twentieth century, Vietnam faced a lot of hardship owing to the Vietnam War. People born in pre-1951 had to live under challenging conditions and were not entitled to any dental care for over 30 years. Furthermore, as far as we know there have been no studies regarding tooth loss among the Vietnamese population.

Thus, the aim of the present study was to investigate tooth loss and related risk factors among elderly Vietnamese aged 65-74.

\section{*Corresponding author:}

Professor Mare Saag, DDS, PhD, Institute of Dentistry, University of Tartu

Tel: +3727319855, Fax: +3727319856, e-mail: Mare.Saag@ut.ee 


\section{Methodology}

\subsection{Study sample}

This cross-sectional study involved elderly people aged 65-74 years old, living in Danang, Vietnam. The participants were selected according to a multistage stratified random sampling method based on demographic characteristics.

Danang is subdivided into six urban districts and two rural districts. In the first stage of the current study, three urban districts and one rural district were randomly selected including Hai Chau, Thanh Khe, Cam Le, and Hoa Vang. The second stage, the lists of the elderly aged 65-74 were obtained from the community unions for elderly adults into which include all the citizens over 60 years of age. Fortyfive participants from each of the selected urban districts and 135 participants from the rural district were randomly sampled and stratified into groups by gender and age (male:female ratio $1: 1$, and 65 69:70-74 years old 1:1). After factoring in $10 \%$ of compensation for the possible decline of survey participants, the total sample consisted of 300 participants; however, 42 participants withdrew during the study. Thus, the final sample was 258 participants including 128 females and 130 males. A written informed consent was obtained from each participant. Selected participants were mentally healthy persons who were able to answer questionnaires about their oral health status. The examination was performed at the local health centre or the dental clinic of the Danang University of Medical Technology and Pharmacy. Two dental students were trained to ask the questions and record the answers on an assessment form. The first author conducted all clinical oral examinations. Ten percent of the participants were re-examined to test the reliability of the collected data. The intrarater reliability between studies was above 0.9 .

\subsection{Evaluation of tooth loss}

Each absent tooth regardless of the circumstances would be registered as a tooth loss. In the case of at least one existing third molar, the other third molar loss was recorded. Recording all third molars would be excluded if all of them were not present during the dental examination.

The number of lost teeth was classified into categories: 1) No tooth loss; 2)1-3 lost teeth; 3) 4-6 lost teeth; 4) 7-16 lost teeth; 5) > 16 lost teeth. The number of lost teeth was also dichotomized into $\leq 6$ lost teeth or $>6$ lost teeth. The position of any lost tooth based on tooth functional groups, such as incisors, canines, premolars, and molars was also determined for both upper and lower jaws.

\subsection{Evaluation of risk factors}

The assessment of tooth loss risk factors was based on the Oral Health Questionnaire for adults (WHO, 2013). Personal interviews were conducted before the dental examination, and data from the questionnaires were categorised into the bivariate classes:

Sociodemographic factors: gender (female, male); age group (65-69, 70-74); place of residence (rural, urban); time in education ( $\leq 5$ years, $>5$ years).
Oral health behaviours: Participants were asked the following questions: "How often do you clean your teeth?" (Categorised as: $\geq 2$ times/day or $\leq$ 1 time/day); "How long is it since you last visited a dentist?" ( $\leq 1$ year or $>1$ year); "Do you smoke tobacco, consume alcohol or have any chronic disease?" (Yes or no).

This study was registered and approved by the Human Research Ethics Committee of the Da Nang University of Medical Technology \& Pharmacy and performed according to the World Medical Association Declaration of Helsinki.

\subsection{Statistical methods}

Data entry and statistical analyses were performed in version 17.0 of the Statistical Package for Social Sciences (SPSS). The Student's t-test, Chi-square test were used to analyse correlations between tooth loss status and risk factors. Binomial logistic regression was used to determine the odds of having $>6$ lost teeth. A confidence level of $95 \%$ and a two-tailed $p$-value of 0.05 were used to determine any significant difference.

\section{Results}

Among the 258 elderly Vietnamese, the prevalence of missing, at least, one incisor, canine, premolar or molar were $42.2 \%, 20.9 \%, 50.4 \%$ and $89.1 \%$ respectively. The prevalence of tooth loss (canines, premolars, and molars) in the upper jaw was statistically higher than in the lower jaw, except for incisors $(p<0.01)$ (Table 1 and Figure 1).

$\begin{array}{llllllllllllllll}18 & 17 & 16 & 15 & 14 & 13 & 12 & 11 & 21 & 22 & 23 & 24 & 25 & 26 & 27 & 28\end{array}$

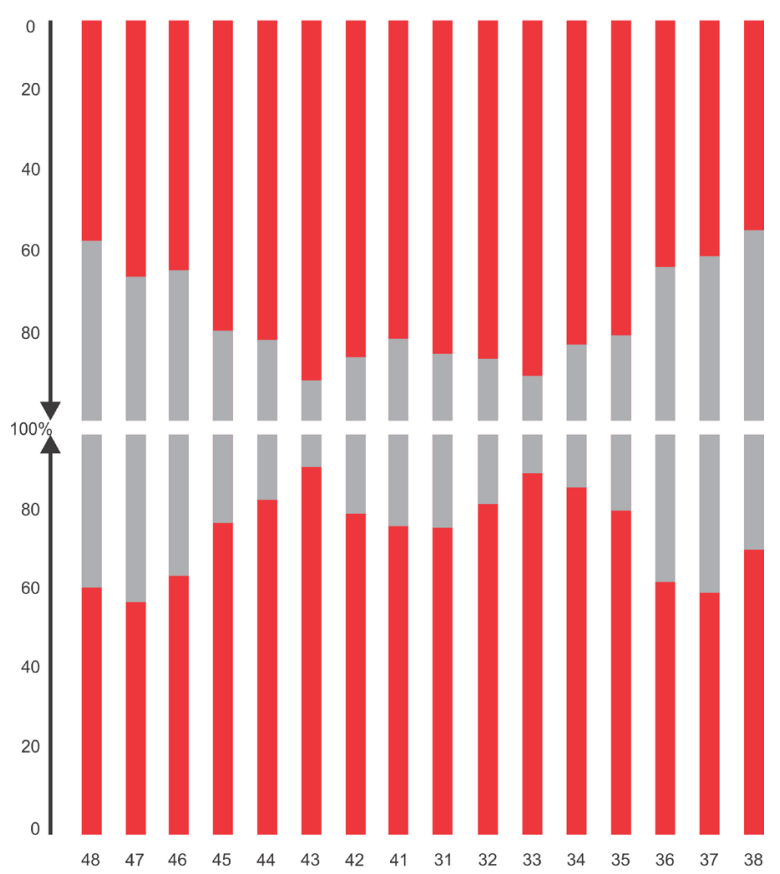

Figure 1. The distribution of tooth loss among elderly Vietnamese (red -Residual teeth; grey Missing teeth)

Table 2 shows that the mean tooth loss for the sample was $7.6( \pm 7.0)$. Within each category of predictors, a statistically higher number of lost teeth was found for: the 70-74 age group 
(Mean \pm SD, 8.8 \pm 7.9 ); rural residents $(8.8 \pm 7.6)$; time in education $\leq 5$ years $(10.2 \pm 7.7)$; frequency of teeth cleaning $\leq 1$ time/day $(8.7 \pm 7.3)$; last visit to dentist $>1$ year ago $(8.2 \pm 7.5)$; tobacco smoking (9.4 \pm 7.6$)$, and no alcohol drinking (8.3 \pm 7.2$)$.

Table 1. The prevalence of tooth loss for each functional group among elderly Vietnamese

\begin{tabular}{|c|c|c|c|c|}
\hline \multirow{2}{*}{ Functional group } & \multicolumn{3}{|c|}{ Prevalence of tooth loss (\%) } & \multirow[b]{2}{*}{$p$-value } \\
\hline & Upper jaw & Lower jaw & Both & \\
\hline Incisor & 27.9 & 30.6 & 42.2 & $<0.001$ \\
\hline Canine & 15.5 & 12.0 & 20.9 & $<0.001$ \\
\hline Premolar & 37.6 & 34.1 & 50.4 & $<0.001$ \\
\hline Molar & 77.5 & 74.8 & 89.1 & $<0.001$ \\
\hline
\end{tabular}

Chi-square test

According to the distribution of a number of lost teeth, $27.1 \%$ of the elderly participants had lost 1-3 teeth, 23.6\% 4-6 teeth, 27.1\% 7-16 teeth and $13.6 \%>16$ teeth; only $8.6 \%$ had full dentition. There was a significant correlation between the distribution of a number of lost teeth and time in education, and alcohol drinking $(p<0.05$, Table 2$)$.
Having $>6$ lost teeth was statistically significantly related to time in education, frequency of cleaning teeth, tobacco smoking and alcohol drinking (Table 2). However, the odds ratio of losing $>6$ teeth was calculated for time in education, tobacco smoking and alcohol drinking.

Table 2. Mean tooth loss and tooth number class percentages in relation to risk factors

\begin{tabular}{|c|c|c|c|c|c|c|c|c|c|c|c|c|}
\hline \multirow[t]{2}{*}{ Variables } & \multirow[t]{2}{*}{$\mathrm{n}(\%)$} & \multirow{2}{*}{$\begin{array}{c}\text { Tooth } \\
\text { loss } \\
\text { Mean } \pm \\
\text { SD }\end{array}$} & \multirow{2}{*}{$\begin{array}{c}p- \\
\text { value }\end{array}$} & \multicolumn{5}{|c|}{ Number of lost teeth (\%) } & \multirow{2}{*}{$\begin{array}{c}p- \\
\text { value }\end{array}$} & \multicolumn{2}{|c|}{$\begin{array}{c}\text { Dichotomized } \\
\text { number } \\
\text { of lost teeth }\end{array}$} & \multirow{2}{*}{$\begin{array}{c}p- \\
\text { value }^{b}\end{array}$} \\
\hline & & & & 0 & $1-3$ & 4-6 & $7-16$ & $>16$ & & $\leq 6$ & $>6$ & \\
\hline \multicolumn{13}{|l|}{ Age } \\
\hline$\frac{65-69}{70-74}$ & $\frac{129(50)}{129(50)}$ & $\frac{6.6 \pm 6.0}{8.8 \pm 7.9}$ & $0.01^{*}$ & $\frac{10.1}{7.0}$ & $\frac{26.3}{27.9}$ & $\frac{28.7}{186}$ & 26.4 & $\begin{array}{c}8.5 \\
186\end{array}$ & \multirow[t]{2}{*}{0.07} & $\frac{65.1}{53.5}$ & $\frac{34.9}{46.5}$ & 0.06 \\
\hline \multicolumn{12}{|l|}{ Gender } & \\
\hline$\frac{\text { Female }}{\text { Male }}$ & $\frac{128(49.6)}{130(50.4)}$ & $\frac{8.4 \pm 7.0}{7.1 \pm 71}$ & 0.14 & $\frac{9.4}{77}$ & $\frac{18.8}{35.4}$ & $\frac{25.8}{215}$ & $\frac{31.2}{231}$ & $\frac{14.8}{12.3}$ & \multirow[t]{2}{*}{0.06} & $\frac{53.9}{64.6}$ & $\frac{46.1}{35.4}$ & 0.08 \\
\hline \multicolumn{12}{|l|}{ Residence } & \\
\hline$\frac{\text { Rural }}{\text { Irhan }}$ & $\frac{121(46.9)}{137(531)}$ & $\frac{8.8 \pm 7.6}{67+64}$ & $0.01^{*}$ & $\frac{6.6}{102}$ & $\frac{22.3}{314}$ & $\overline{0}$ & $\frac{27.3}{270}$ & $\frac{18.2}{0.5}$ & \multirow[t]{2}{*}{0.14} & $\frac{54.5}{6.23}$ & $\frac{45.5}{3.5}$ & 0.14 \\
\hline \multicolumn{12}{|c|}{ Time in education } & \\
\hline$\leq 5$ years & $105(40.7)$ & $\begin{array}{c}10.2 \pm \\
77\end{array}$ & \multirow[t]{2}{*}{$<0.001$} & 3.8 & 19.0 & 21.9 & 33.3 & 21.9 & \multirow{2}{*}{$<0.001$} & \multicolumn{2}{|l|}{44.8} & \multirow{2}{*}{$<0.001$} \\
\hline$>5$ years & $153(59.3)$ & $6.0 \pm 5.9$ & & 11.8 & 32.7 & 24.8 & 22.9 & 7.8 & & 69.3 & 30.7 & \\
\hline \multirow{3}{*}{$\begin{array}{c}\text { Frequency } \\
\leq 1 \text { time/day } \\
\geq 2 \text { times/ } \\
\text { dav }\end{array}$} & eaning te & & & & & & & & & & & \\
\hline & 132 & $8.7 \pm 7.3$ & \multirow[b]{2}{*}{$0.01^{*}$} & 6.8 & \multirow{2}{*}{$\frac{24.2}{29.0}$} & \multirow{2}{*}{$\frac{21.2}{26.6}$} & \multirow{2}{*}{\begin{tabular}{|l|}
32.6 \\
21.8
\end{tabular}} & \multirow{2}{*}{\begin{tabular}{|l|}
15.2 \\
12.1 \\
\end{tabular}} & \multirow[b]{2}{*}{0.24} & 52.3 & 47.7 & \multirow[b]{2}{*}{$0.02^{*}$} \\
\hline & $124(48.4)$ & $6.8 \pm 6.7$ & & 10.5 & & & & & & 66.1 & 33.9 & \\
\hline Last visitt & entis & & & & & & & & & & & \\
\hline$>1$ year & $191(74.6)$ & $8.2 \pm 7.5$ & $002^{*}$ & 8.9 & 23.0 & 25.1 & 26.7 & 16.2 & 009 & 57.1 & 42.9 & 028 \\
\hline Tobaccosi & ing & & & & & & & & & & & \\
\hline Yes & $60(23,4)$ & $\frac{9.4 \pm 7.6}{7.2}$ & $0.04^{*}$ & $\frac{8.3}{0.7}$ & 21.7 & 5.0 & $\frac{38.3}{2,10}$ & 16.7 & 0.12 & 45.0 & $\frac{55.0}{3.7}$ & $0.01^{*}$ \\
\hline Alcohold & $\frac{190(10.0)}{\sin }$ & & & & & & & & & & & \\
\hline Yes & $56(21.9)$ & $5.9 \pm 6.4$ & 0 ר & 1.1 & 44.7 & 21.4 & 19.7 & 7. & 00 & 73.2 & 26.8 & $001^{*}$ \\
\hline No & $200(78.1)$ & $8.3 \pm 7.2$ & 0.02 & 9.0 & 21.5 & 24.5 & 29.5 & 15.5 & 0.01 & 55.0 & 45.0 & $0.01^{*}$ \\
\hline$\frac{\text { hronic di }}{Y e s}$ & & & & & & & & & & & & \\
\hline$\frac{\text { res }}{\text { No }}$ & $\frac{138(53.9)}{118(46.1)}$ & $\frac{1.0 \pm 1.1}{8.5+6.9}$ & 0.10 & $\frac{9.4}{76}$ & $\frac{32.1}{19.5}$ & $\frac{21.1}{26^{2}}$ & $\frac{23.2}{32 ?}$ & $\frac{13.0}{14}$ & 0.14 & $\frac{63.8}{534}$ & 36.2 & 0.09 \\
\hline Total & $\frac{10140.11}{258}$ & $\frac{0.01 .1}{76 \pm 7.0}$ & & $\frac{1.0}{8.6}$ & $\frac{17}{271}$ & $\frac{20.5}{23.6}$ & $\frac{32}{271}$ & $\frac{14.4}{13.6}$ & & $\frac{2.4}{59.3}$ & $\frac{40.0}{40.7}$ & \\
\hline
\end{tabular}

aStudent's t-test

${ }^{b}$ Chi-square test

${ }^{*} p<0.05$

Table 3 shows the odds of having $>6$ lost teeth was significantly more frequent among elderly persons with less time in education $(\mathrm{OR}=2.2, p<0.01)$ and tobacco smoking $(\mathrm{OR}=2.8, p<0.01)$. However, alcohol drinking was significantly inversely associated with $>6$ lost teeth $(O R=0.3, p<0.01)$.

\section{Discussion}

The main finding of this study was that there was a high prevalence of tooth loss among the elderly Vietnamese aged 65-74. Tooth loss might impact the general health, cause the loss of mastication and reduce the quality of life $e^{2,3}$.

Over ninety percent of the elderly Vietnamese presented tooth loss condition. This result was in line with the study conducted in the South Vietnam where $96 \%$ of the older population had missing teeth ${ }^{11}$. We found that posterior teeth lost more 
often than anterior teeth. This finding is expected because of the morphology of the occlusal surfaces of posterior teeth, which easily accumulates plaque and food debris. Furthermore, it was often difficult for the elders to perform oral hygiene on the last position of the dental arch, and this could increase the risk of caries and periodontitis, leading to tooth loss.

We observed that the prevalence of losing canine and posterior teeth of the maxilla were statistically higher than that of the mandible. The maxilla is known as the spongy bone type, and the mandibular is of the compact bone type; consequently, inflammation of the supporting bone in the maxilla could lead to a more rapid resorption of bone and earlier tooth loss than in the mandibular ${ }^{12}$. However, our finding was in contrast with the study of Nguyen et al. ${ }^{11}$, which indicated that loss of lower posterior teeth was more frequent than that of upper posterior teeth.
The elderly Vietnamese had an average of 7.6 missing teeth. At the same age group, this observed number is higher compared to the study conducted in Australia (5.3) $)^{13}$, Turkey $(7.0)^{14}$, but lower than the one reported in China $(11.2)^{8}$, and Brazil (26.1 $)^{15}$. Regarding the influence of sociodemographic factors on tooth loss, participants aged 70-74 had lost significantly more teeth on average than those aged 65-69. This finding was in agreement with previous studies, which indicated that the number of lost teeth tends to increase with age ${ }^{14,15}$.

Maintaining more than 20 teeth is a core mission of Oral health care programmes for the older population ${ }^{16}$. Approximately $60 \%$ of the elderly Vietnamese still had 20 teeth or more. This prevalence was far lower compared with the findings in a neighbouring country ${ }^{17}$, but in line with a study conducted in $\operatorname{Iran}^{18}$, and higher than the ones reported in Turkey ${ }^{14}$.

Table 1. The odds of $>6$ lost teeth in relation to risk factors

\begin{tabular}{|c|c|c|c|}
\hline \multirow[b]{2}{*}{ Variables } & \multicolumn{3}{|c|}{ Odds ratio } \\
\hline & OR & $95 \% \mathrm{Cl}$ & $p$-value \\
\hline \multicolumn{4}{|l|}{ Frequency of cleaning teeth } \\
\hline$\geq 2$ times/dav & 1.0(ref) & & \\
\hline$\leq 1$ time/day & 1.4 & $0.8-2.7$ & 0.15 \\
\hline \multicolumn{4}{|l|}{ Time in education } \\
\hline$>5$ years & 1.0(ref) & & \\
\hline$\leq 5$ years & 2.2 & $1.3-3.8$ & $0.004^{*}$ \\
\hline \multicolumn{4}{|l|}{ Tobacco smoking } \\
\hline No & 1.0 (ref) & & \\
\hline Dring aleahel & 2.8 & $1.4-5.6$ & $0.003^{*}$ \\
\hline \multicolumn{4}{|l|}{ Drinkalcohol } \\
\hline Yes & 0.3 & $0.1-0.7$ & $0.003^{*}$ \\
\hline
\end{tabular}

Binary logistic regression

Ref: reference, ${ }^{\star} p<0.01$

Rural residents had significantly higher tooth loss than urban residents. This reflected the difference in oral health services among regions in Vietnam where the density of dentists in the rural area was much lower than in the urban area $(1 / 200,000$ for rural vs. 1/13,500 inhabitants for urban $)^{11}$. Moreover, the elderly Vietnamese living in a rural area often prefer to remove a painful tooth rather than having it restored because they think that tooth loss is a natural part of the aging process.

The frequency of dental visits reflect the attitudes of the patient or the provider, accessibility to dental care and prevailing societal attitudes regarding oral health care. We found that $74.6 \%$ of the elderly Vietnamese ignored an oral health checkup during the previous year, they only visited dentists with the unique aim to remove teeth due to an acute toothache or an impaired ability to chew (i.e. mobility teeth). Moreover, material and transportation-related obstacles, especially in the rural areas, are also factors that limit access to oral health care services ${ }^{19,20}$. Therefore, the number of teeth lost in this group was much higher than those who annually visited the dentist for oral care. Our finding was close to the third China National
Oral Health Survey. This survey reported that more than three-fourths of the Chinese aged 65-74 had missing teeth more often than those who regularly visited a dentist ${ }^{8}$.

The risk factors for tooth loss have been studied all over the world. However, as far as we know, no data have been reported on the risk factors of tooth loss in Vietnam. Lack of knowledge among the elderly Vietnamese regarding oral health might be influenced by the level of education ${ }^{21}$. Forty percent of the elderly Vietnamese in the current study who were in education $\leq 5$ years had lost 10.2 teeth on average. Their education might have been interrupted due to the Vietnam War (19451975). The subjects believe that the prolonging the existence of a tooth in their mouth would have an adverse impact on the life of their descendants. Also, the elders with less time in education were significantly associated with the odds of losing $>6$ teeth $(\mathrm{OR}=2.2)$, it might be due to the lack of awareness about oral health behaviours for maintaining teeth.

In the current study, we found that smokers (23.4\%) had significantly higher tooth loss $(9.3 \pm 7.6)$ than non-smokers (7.2 \pm 6.8 ). It could be due to the well- 
known fact that tobacco smoking can increase the risk for periodontitis. Substances in tobacco might facilitate the accumulation of bacteria and lead to the destruction of tooth-supporting tissue $^{22}$. Our study indicated that the odds ratio for smokers losing $>6$ teeth was 2.8 as compared to non-smokers. These results are similar to those of studies in Japan and China ${ }^{23,8}$. Reports about the relationship between alcohol consumption and tooth loss have been focused on dose-related effects. Some studies have shown that drinking causes periodontitis, with the latter considered a risk factor for tooth loss ${ }^{7,24}$. However, alcohol consumption was not considered as indicator for losing $>6$ teeth in the current study. The similar findings were also reported by Yoshioka et al. ${ }^{23}$ and Eustaquio-Raga et al. ${ }^{25}$

The shortcomings of our study were that the quantity and frequency of alcohol consumption were not accurately measured, and the reason for tooth loss (due to dental caries or periodontal disease) could not be exactly determined. A further study is required to investigate the impact of tooth loss on the function of the stomatognathic system in the elderly persons.

\section{Conclusions}

The data obtained allowed us to conclude that there were high prevalence and a high number of teeth lost among elderly Vietnamese. Smoking behaviour and time in education were significantly related to maintaining teeth of the elderly community population. The data serve setting up an oral health intervention programme for the older Vietnamese.

\section{Acknowledgements}

This study was supported by an Estonian Science Foundation grant (No. 9255), IUT20-46 grant from the Estonian Research Council and the DoRa Doctoral Studies and Internationalisation Programme. The authors declare no conflict of interest related to this study.

\section{REFERENCES}

1. Petersen PE, Kandelman D, Arpin S, Ogawa H. Global oral health of older people--call for public health action. Community Dent Health. 2010;27(4):257-267.

2. Dietrich T, Jimenez M, Krall Kaye EA, Vokonas PS, Garcia RI. Age-dependent associations between chronic periodontitis/ edentulism and risk of coronary heart disease. Circulation. 2008:117(13):1668-1674.

3. Ikebe K, Matsuda K, Kagawa R, Enoki K, Okada T, Yoshida M, et al. Masticatory performance in older subjects with varying degrees of tooth loss. J Dent. 2012;40(1):71-76.

4. Giusti L, Salmon ES, White R. Impact of Attitudes and Behaviors on Tooth Loss. Stoma Edu J. 2014;1(2):123-130.

5. Jiang Y, Okoro CA, Oh J, Fuller DL. Sociodemographic and health-related risk factors associated with tooth loss among adults in Rhode Island. Prev Chronic Dis. 2013;10:1-12.

6. Wang MQ, Xue F, He JJ, Chen JH, Chen CS, Raustia A. Missing posterior teeth and risk of temporomandibular disorders. J Dent Res. 2009:88(10):942-945.

7. Kim HS, Son JH, Yi HY, Hong HK, Suh HJ, Bae KH. Association between harmful alcohol use and periodontal status according to gender and smoking. BMC Oral Health. 2014;14:1-6.

8. Liu L, Zhang Y, Wu W, Cheng M, Li Y, Cheng R. Prevalence and correlates of dental caries in an elderly population in northeast China. PloS One. 2013;8(11):1-6

9. Musacchio E, Perissinotto E, Binotto P, Sartori L, Silva-Netto F, Zambon S, Manzato E, Corti MC, Baggio G, Crepaldi G. Tooth loss in the elderly and its association with nutritional status, socio-economic and lifestyle factors. Acta Odontol Scand. 2007;65(2):78-86

10. Morse DE, Avlund K, Christensen LB, Fiehn NE, Molbo D Holmstrup P, Kongstad J, Mortensen EL, Holm-Pedersen P. Smoking and drinking as risk indicators for tooth loss in middleaged Danes. J Aging Health. 2014;26(1):54-71.

11. Nguyen TC, Witter DJ, Bronkhorst EM, Truong NB, Creugers $\mathrm{NH}$. Oral health status of adults in Southern Vietnam - a cross-sectional epidemiological study. BMC Oral Health. 2010;10:1-11.

12. Parkinson CF. Similarities in resorption patterns of maxillary and mandibular ridges. J Prosthet Dent. 1978;39(6):598-602

13. Slade GD, Spencer AJ, Roberts-Thomson KF. Australia's dental generations, The National Survey of Adult Oral Health 2004-2006. Canberra: Australian Institute of Health and
Welfare; 2007.

14. Doğan BG, Gökalp S. Tooth loss and edentulism in the Turkish elderly. Arch Gerontol Geriatr. 2012;54(2):162-166.

15. Moreira Rda S, Nico LS, Tomita NE. Oral health conditions among the elderly in Southeastern São Paulo State. J Appl Oral Sci. 2009;17(3):170-178.

16. Mersel A. Prevention for the elderly patients. Stoma Edu J. 2014; $1(1): 10$

17. Yiengprugsawan V, Somkotra T, Seubsman S, Sleigh AC; Tha Cohort Study Team. Oral Health-Related Quality of Life among a large national cohort of 87,134 Thai adults. Health Qual Life Outcomes. 2011:9:1-8.

18. Khazaei S, Keshteli AH, Feizi A, Savabi O, Adibi P. Epidemiology and risk factors of tooth loss among Iranian adults: findings from a large community-based study. Biomed Res Int. 2013;2013:1-8.

19. Klein BE, Klein R, Knudtson MD. Life-style correlates of tooth loss in an adult Midwestern population. J Public Health Dent. 2004;64(3):145-150.

20. Susin C, Oppermann RV, Haugejorden O, Albandar JM. Tooth loss and associated risk indicators in an adult urban population from south Brazil. Acta Odontol Scand. 2005;63(2):85-93. 21. Leggett A, Zarit SH, Hoang CN, Nguyen HT. Correlates of cognitive impairment in older Vietnamese. Aging Ment Health. 2013;17(8):915-923.

22. Hanioka T, Ojima M, Tanaka K, Matsuo K, Sato F, Tanaka H. Causal assessment of smoking and tooth loss: a systematic review of observational studies. BMC Public Health. 2011:11:1-10 23. Yoshioka M, Hinode D, Yokoyama M, Fujiwara A, Sakaida Y, Toyoshima K. Relationship between subjective oral health status and lifestyle in elderly people: a cross-sectional study in Japan. ISRN Dent. 2013;2013:1-6.

24. Okamoto $Y$, Tsuboi $S$, Suzuki S, Nakagaki H, Ogura $Y$, Maeda K, Tokudome S. Effects of smoking and drinking habits on the incidence of periodontal disease and tooth loss among Japanese males: a 4-yr longitudinal study. J Periodontal Res. 2006;41(6):560-566.

25. Eustaquio-Raga MV, Montiel-Company JM, Almerich-Silla JM. Factors associated with edentulousness in an elderly population in Valencia (Spain). Gac Sanit. 2013; 27(2): 123-127. 


\section{Minh Son NGUYEN \\ DDS, PhD student \\ Institute of Dentistry, University of Tartu, Estonia Head of the Prosthodontic Department \\ Da Nang University of Medical Technology and Pharmacy \\ Da Nang, Vietnam}

Dr. Nguyen Minh Son is a Prosthodontist. He is currently a PhD student at the University of Tartu (20142018). He completed the dental curriculum at the Hue University of Medicine and Pharmacy in 2007. He has been a lecturer at the Da Nang University of Medical Technology and Pharmacy Vietnam since 2008 and he was appointed Head of the Prosthodontic Department in 2014. His research is related to prosthodontics, community dental health, and geriatric dentistry. He currently co-operates with the Institute of Dentistry, the University of Tartu for research related to temporomandibular disorders among the Vietnamese elderly, the oral health of Vietnamese schoolchildren, and malocclusion in Vietnamese Osteogenesis Imperfecta. He was awarded the 1st award at the annual conference of the Faculty of Medicine, University of Tartu, 2015 and the First prize at the National Scientific Conference in Medicine and Pharmacy for Vietnamese Young Researchers, in 2010 and 2012.

\section{Ouestions}

\section{According to the WHO, which age group represents the older population in the oral health survey?}

口a. Over 60 years old;

b. From 60 to 80 years old;

ac. From 65 to 74 years old;

$\square$ d. It depends on the method of study.

\section{According to the WHO, as the target of oral health care older people have to:}

$\square$ a. Maintain at least 20 functional teeth;

b. Maintain at least 16 functional teeth;

$\square$ c. Visit a dentist twice a year;

$\square$ d. Have prosthesis to replace the missing teeth.

\section{According the Oral health survey of WHO for the older population, the M component in the DMFT index represents a missing tooth due to:}

$\square$ a. Dental caries, excluding the third molar;

b. Periodontal disease, excluding the third molar;

ac. Dental caries and periodontal disease, excluding the third molar;

$\square d$. Any reason, including the third molar.

\section{Which score of DMFT represents a high level of dental caries among the older popu- lation?}
口a. DMFT $\geq 8$
b. $D M F T \geq 10$;
口. $D M F T \geq 12$;
ad. $D M F T \geq 14$ 